\title{
Compact Printed Multiband Antenna with Independent Setting Suitable for Fixed and Reconfigurable Wireless Communication Systems
}

\author{
Hattan F. Abutarboush, Member, IEEE; R. Nilavalan, Senior Member, IEEE; S. W. Cheung, Senior \\ Member, IEEE; and K. Nasr, Senior Member, IEEE
}

\begin{abstract}
This paper presents the design of a low-profile compact printed antenna for fixed frequency and reconfigurable frequency bands. The antenna consists of a main patch, four subpatches, and a ground plane to generate five frequency bands, at $0.92,1.73,1.98,2.4$, and $2.9 \mathrm{GHz}$, for different wireless systems. For the fixed-frequency design, the five individual frequency bands can be adjusted and set independently over the wide ranges of $18.78 \%, 22.75 \%, 4.51 \%, 11 \%$, and $8.21 \%$, respectively, using just one parameter of the antenna. By putting a varactor (diode) at each of the sub-patch inputs, four of the frequency bands can be controlled independently over wide ranges and the antenna has a reconfigurable design. The tunability ranges for the four bands of $0.92,1.73,1.98$, and $2.9 \mathrm{GHz}$ are $23.5 \%$, $10.30 \%, 13.5 \%$, and $3 \%$, respectively. The fixed and reconfigurable designs are studied using computer simulation. For verification of simulation results, the two designs are fabricated and the prototypes are measured. The results show a good agreement between simulated and measured results.
\end{abstract}

Index Terms - Small antenna, Multiband antenna, Reconfigurable antenna, Fixed antenna, Independent control, wide tuning range, Cognitive radio

\section{INTRODUCTION}

$\mathrm{D}$ IFFERENT techniques to achieve multiband operations for compact antennas using planar technology have been investigated. These techniques include using different slot shapes [1]-[7], shorting walls and V-shaped configuration [8], stack and multi-layers [9], and fractal shape in the ground plane [9]-[10]. Recently, independent control in frequencies for multiband antennas has received much attention. For example, in [11] a planar inverted-F antenna (PIFA) with a relatively large size of $105 \times 30 \times 9 \mathrm{~mm} 3$ was studied to control three resonant frequencies. In [12] a multi-

Manuscript received January 09, 2011

Hattan F. Abutarboush was with Brunel University, London, UK and now he is with the Electrical Engineering, King Abdullah University of Science and Technology (KAUST), Saudi Arabia.

e-mail: (Hattan.Abutarboush@ieee.org).

R. Nilavalan is with the Wireless Networks and Communications Centre (WNCC), School of Engineering and Design, Brunel University, London, UB8 3PH.UK.

S. W. Cheung is with the Department of Electrical and Electronics Engineering, The Hong Kong University, Hong Kong.

K. Nasr is with the National Physical Laboratory (NPL), Teddington, TW11 0LW, UK. frequency band antenna was designed to control the lowfrequency band and first high-frequency band. In [13] a PIFA was studied to independently control three frequency bands between 1.5 and $6.8 \mathrm{GHz}$.

Fixed multiband antennas lack the flexibility to accommodate new services compared with frequency-reconfigurable antennas [14]; the latter antennas can be classified into two categories: continuous tuning and discrete tuning. Continuous tuning can be achieved using varactor diodes; the antennas can be tuned to have smooth transitions within or between operating bands [15]-[24]. Discrete tuning can be achieved using PIN-diode switches; the operating frequencies can be switched among different services, depending on the switching states [25]-[27]. All the designs in [15] to [29] were limited to single- or dual-band operations.

A number of techniques have been proposed for reconfigurable antennas to achieve independent tuning for one or more frequency bands over wide ranges. For example, in [22] a reconfigurable dual-band antenna was designed with a wide tuning range of $2.02 \mathrm{GHz}$. However, a high voltage of 30 $\mathrm{V}$ was required, and the size of the antenna was large at $150 \times 110 \mathrm{~mm} 2$. In [23] a reconfigurable dual-band dual-port chassis-antenna was designed for a wide tuning range. In this design, the antenna was of high profile with $7 \mathrm{~mm}$ and so was not suitable for slim devices. In [24] a square-ring dual-band antenna was designed; it had a fixed upper resonant frequency and a tunable lower resonant frequency. All these techniques have the problem of 1) requiring high voltages to perform tuning, 2) being high profile, 3) being large in size, or 4) having small tuning ranges.

This paper presents the design of a compact antenna for fixed and reconfigurable frequency bands. The antenna employs a main patch and four sub-patches to generate five frequency bands. In the fixed-frequency design, the frequency bands can be set independently over a wide range using just one key parameter of the antenna. For the reconfigurable design, the frequency bands can be independently controlled/tuned using varactors.

This paper is a further study of [30] and [31]. This further study includes the design methodology, frequency setting in the fixed design, and independent tuning in the reconfigurable design. It also includes the radiation patterns for the reconfigurable design, and the efficiency and gain comparison for the fixed and reconfigurable designs. 


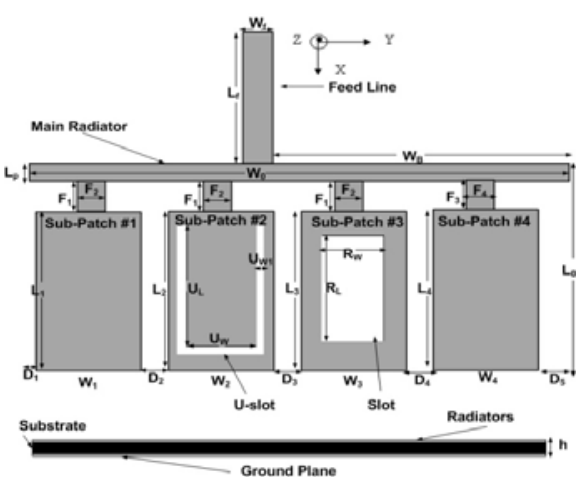

(a)

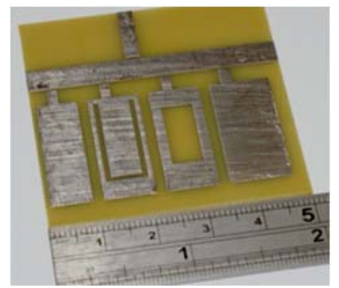

(b)

Fig. 1. (a) Structure of proposed fixed-design antenna and (b) prototype of fixed-design antenna

\section{Design of Fixed Multiband Antenna}

\section{A. Design of Fixed Multiband Antenna}

Figure 1(a) shows the geometry of the antenna, having five frequency bands, numbered $1,2,3,4$, and 5 at $0.92,1.73$, $1.98,2.4$, and $2.9 \mathrm{GHz}$, respectively. Table I lists the key parameters. The antenna consists of a main patch, four subpatches (sub-patches 1, 2, 3, and 4), a ground plane, and a 50$\Omega$ feed line. The antenna is designed on an FR-4 substrate with a thickness of $1.57 \mathrm{~mm}$ and a relative permittivity of 4.4 , occupying an area of $45.6 \times 50 \mathrm{~mm}^{2}$ on one side of the substrate and an area of $50 \times 50 \mathrm{~mm}^{2}$ for the ground plane on the other side. The design steps can be described with the aid of Fig. 2(a) to (e) as follows:

Step 1: The main radiator is designed to generate band 4 at 2.4 $\mathrm{GHz}$ for the wireless local area network (WLAN) band, and its dimensions are optimized in terms of minimizing the reflection coefficient $s_{11}$ across the band by computer simulation. Figure 2(a) shows the layout and the optimized $s_{11}$ for the main radiator. At $2.4 \mathrm{GHz}, \mathrm{s}_{11}=-18 \mathrm{~dB}$.

Step 2: Sub-patch 1 is added to the main radiator, as shown in Fig. 2(b), to generate the resonant frequency for band 1 at 0.92 $\mathrm{GHz}$ with $\mathrm{s}_{11}=-7 \mathrm{~dB}$. To make room for adding the sub-patch without increasing the antenna size, the width of the main radiator is reduced from $30 \mathrm{~mm}$ to $4 \mathrm{~mm}$, so the main radiator in Fig. 2(b) looks like a strip line. Adding sub-patch 1 and reducing the width of the patch increase the $s_{11}$ for band 4 at $2.4 \mathrm{GHz}$ from $-18 \mathrm{~dB}$ to about $-7 \mathrm{~dB}$.

Step 3: Sub-patch 2, with layout shown in Fig. 2(c), is added to the main radiator. A U-slot cut on sub-patch 2 is used to generate band 2 at $1.73 \mathrm{GHz}$. Sub-patch 2 does not alter the
TABLE I: DIMENSIONS OF PROPOSED ANTENNA (UNITS IN MM)

\begin{tabular}{|c|c|c|c|c|c|c|c|}
\hline$L_{o}$ & $L_{1}$ & $L_{2}$ & $L_{3}$ & $L_{4}$ & $\mathbf{L}_{f}$ & $L_{P}$ & $W_{o}$ \\
\hline 31 & 24 & 24 & 24 & 24 & 14.6 & 4 & 50 \\
\hline$W_{1}$ & $W_{2}$ & $W_{3}$ & $W_{4}$ & $W_{f}$ & $W_{B}$ & $F_{1}$ & $F_{2}$ \\
\hline 8 & 10 & 10 & 12 & 3 & 27 & 3 & 2 \\
\hline $\boldsymbol{F}_{3}$ & $F_{4}$ & $D_{1}$ & $D_{2}$ & $D_{3}$ & $\mathrm{D}_{4}$ & $\overline{D_{5}}$ & $\boldsymbol{h}$ \\
\hline 3 & 2.5 & 2 & 2 & 2 & 3 & 2 & 1.57 \\
\hline $\mathbf{U}_{\mathbf{L}}$ & $\mathbf{U}_{\mathrm{W}}$ & $\mathbf{R}_{\mathbf{L}}$ & $\mathbf{R}_{\mathrm{W}}$ & $\mathrm{U}_{\mathrm{W} 1}$ & \multicolumn{3}{|c|}{ Total Volume } \\
\hline 19 & 7 & 14 & 6 & 1 & \multicolumn{3}{|c|}{$50 \times 50 \times 1.57 \mathrm{~mm}^{3}$} \\
\hline
\end{tabular}

frequencies for bands 2 and 4 generated by the main patch and sub-patch 1 , respectively, but it lowers their $\mathrm{s}_{11}$ values. Subpatch 2 also generates an unwanted band at $1 \mathrm{GHz}$, which will become insignificant in the final design (in step 5). Note that, without the U-slot, band 2 disappears, as can be seen in Fig. 2(c).

Step 4: Sub-patch 3 is added as shown in Fig. 2(d). A rectangular slot is cut on the sub-patch to generate band 5 at $2.9 \mathrm{GHz}$. It can be seen from Fig. 2(d) that all the bands generated are not affected by sub-patch 3 , except band 1 at $0.92 \mathrm{GHz}$, which is slightly detuned. It will be seen later, however, that adding sub-patch 4 in step 5 will tune the resonant frequency back to $0.92 \mathrm{GHz}$. Note that, without the rectangular slot, band 5 disappears.

Step 5: Sub-patch 4 is added to generate band 3 at $1.98 \mathrm{GHz}$, as shown in Fig. 2(e), resulting in five bands, at 0.92, 1.73, $1.98,2.4$, and $2.9 \mathrm{GHz}$. The $\mathrm{s}_{11}$ values in all five bands are much lower than those without having sub-patch 4. For example, when sub-patch 1 is added to the main radiator in step 1 , the $\mathrm{s}_{11}$ in band 1 is only about $-7 \mathrm{~dB}$. When all the subpatches are added, the $s_{11}$ in band 1 is reduced to more than -10 $\mathrm{dB}$. Thus sub-patch 4 plays a major role in matching. The antenna is fabricated on a substrate, as shown in Fig. 1(b). The $\mathrm{S}_{11}$ of the prototyped antenna is measured and shown in Fig. 2(e) for comparison. The simulated and measured $s_{11}$ are in good agreement. The bandwidths $\left(\mathrm{s}_{11}<-10 \mathrm{~dB}\right)$ for bands 1,2 , 3,4 , and 5 are $45,61,70,140$, and $110 \mathrm{MHz}$, respectively.

\section{B. Current Distribution}

The operations of the antenna at the five resonant frequencies are further studied using surface current distribution. Figure 3 shows the simulated results. For band 1 at $0.92 \mathrm{GHz}$, Fig. 3(a) shows that the current mainly flows on the main radiator and sub-patch 1, and this contributes the most radiation. The other sub-patches simply help improve matching. This explains why, when all sub-patches are added to the main patch, the $s_{11}$ at $0.92 \mathrm{GHz}$ is reduced from $-7 \mathrm{~dB}$ to more than $-10 \mathrm{~dB}$. For band 4 at $2.4 \mathrm{GHz}$, Fig. 3(b) shows that the current is mainly concentrating on the main radiator and sub-patch 1 (xdirection), and this contributes the most radiation. For band 3 at $1.73 \mathrm{GHz}$, Fig. 3(c) shows that the current is mainly concentrating on sub-patch 2 , which contributes the most radiation. Similarly, for bands 5 and 3 at 2.9 and $1.98 \mathrm{GHz}$, respectively, sub-patches 3 and 4 have the highest current densities as shown in Fig. 3(d) and (e) and so are responsible for the corresponding radiation. Figures 3(a) to (e) show the major current paths at the resonant frequencies, corresponding to approximately $0.5 \lambda$, where $\lambda$ is the wavelength at the resonant frequency of the respective band given by $\lambda=\lambda_{0} / \sqrt{\left(\varepsilon_{r}+1\right) / 2}, \lambda_{0}$ being the free space wavelength. 


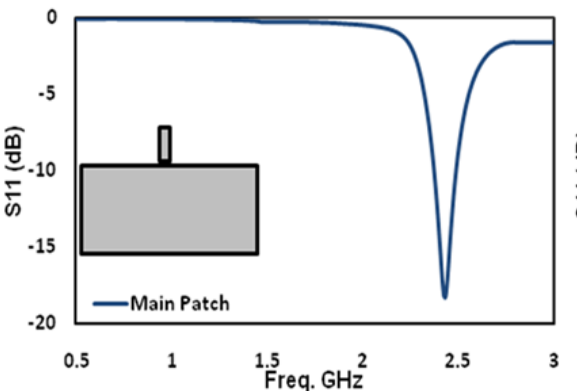

(a)

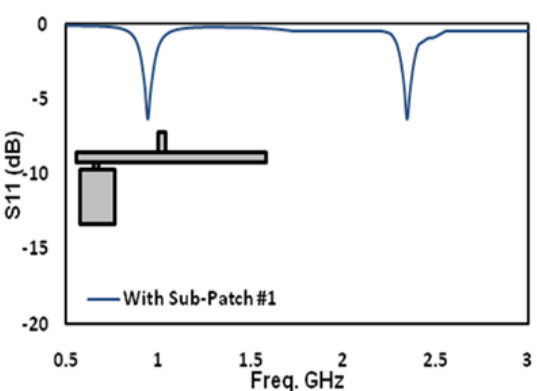

(b)

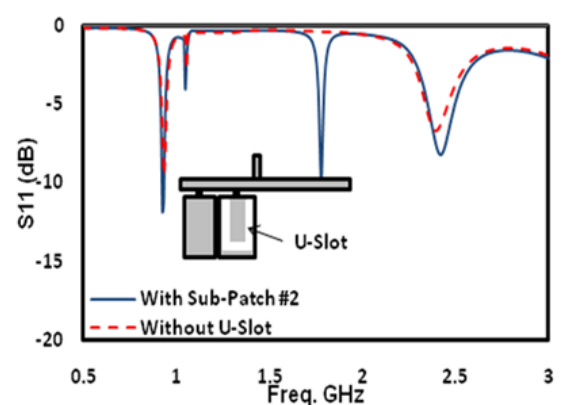

(c)

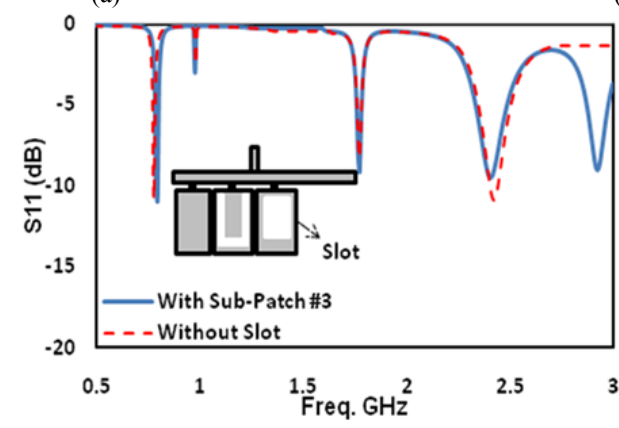

(d)

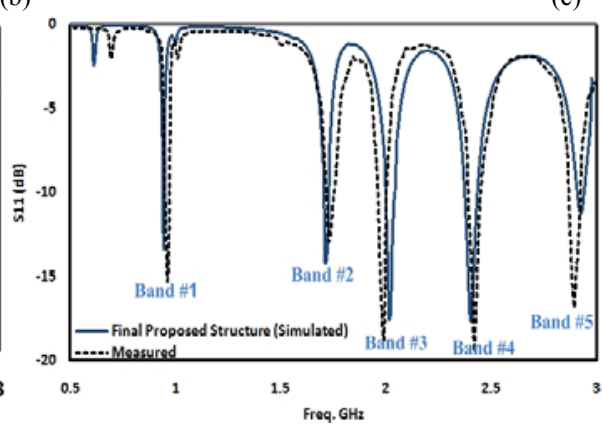

(e)

Fig. 2. Simulated $\mathrm{s}_{11}$ in different design steps for the proposed antenna: (a) main patch, (b) main patch and sub-patch 1, (c) main patch and subpatches 1 and 2 with and without U-slot, (d) main patch and sub-patches 1, 2, and 3 with and without rectangular slot, and (e) final design

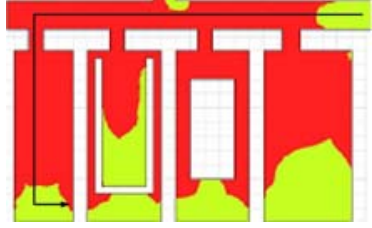

(a)

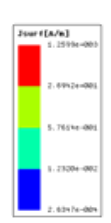

U.

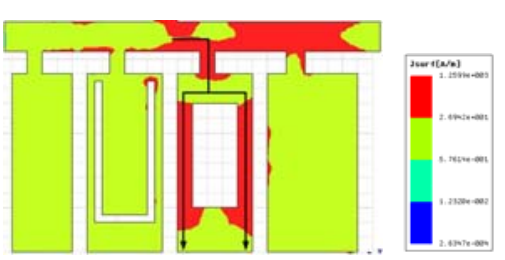

(d)

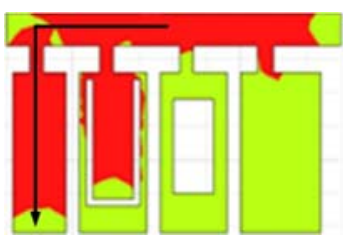

(b)

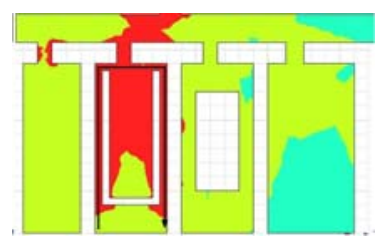

(c)

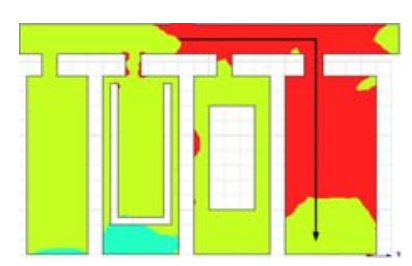

(e)

Fig. 3. Simulated surface current distributions at (a) $0.92 \mathrm{GHz}$, (b) $2.4 \mathrm{GHz}$, (c) $1.73 \mathrm{GHz}$, (d) $2.9 \mathrm{GHz}$ and (e) $1.98 \mathrm{GHz}$.

\section{Independent Control Concept}

In the design of multiband antennas, it is desirable to have the ability to set the frequency bands independently from each other, but achieving this is very challenging [13]. Very often, when some parameters are adjusted to set a band to a particular frequency, the frequencies of all other bands are affected [32]-[35], and so the antenna has to be re-designed. In our multiband antenna, however, we can independently set the individual frequency bands, one by one, without affecting other bands. In our studies, we have identified the current paths responsible for radiation at different resonant frequencies, as shown in Fig. 3. Thus, we can change those antenna parameters, which in turn alter the lengths of the current paths and set the resonant frequencies independently. For example, at $0.92 \mathrm{GHz}$ band, Fig. 3(a) shows that the current travels along sub-patch 1 in the Y-direction. Thus, changing the width $\mathrm{W}_{1}$ of sub-patch 1 alters the resonant frequency $0.92 \mathrm{GHz}$ without much effect on the other bands. At $2.4 \mathrm{GHz}$, Fig. 3(b) shows that the current travels along subpatch 1 in the $\mathrm{X}$-direction, so the length $\mathrm{L}_{1}$ can be used to change this frequency without altering other bands. Applying this same principle to Figs. 3(c) to (e), the lengths $\mathrm{L}_{2}, \mathrm{~L}_{3}$, and $\mathrm{L}_{4}$ in sub-patches 2, 3, and 4, respectively, can be used to independently set the corresponding frequencies 1.73, 2.9, and $1.98 \mathrm{GHz}$ to other values. Figure 4 shows the simulation results on the effects of varying the parameters $W_{1}, L_{1}, L_{2}, L_{3}$, and $\mathrm{L}_{4}$ on the frequency bands. It can be seen from Figs. 4(a) to (e) that the parameters $\mathrm{W}_{1}, \mathrm{~L}_{1}, \mathrm{~L}_{2}, \mathrm{~L}_{3}$, and $\mathrm{L}_{4}$ can be used to independently adjust the frequency bands at $0.92,2.4,1.73$, 2.9 , and $1.98 \mathrm{GHz}$ over the wide ranges of $18.78 \%, 11 \%$, $22.75 \%, 4.51 \%$, and $8.21 \%$, respectively. Table II summarizes these results. 


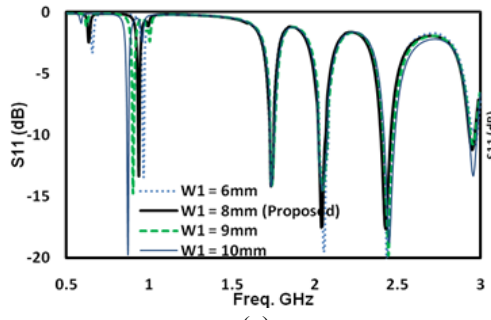

(a)

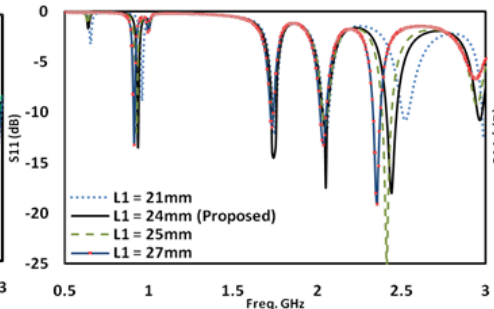

(b)

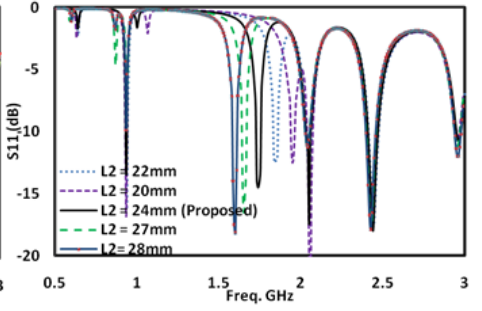

(c)

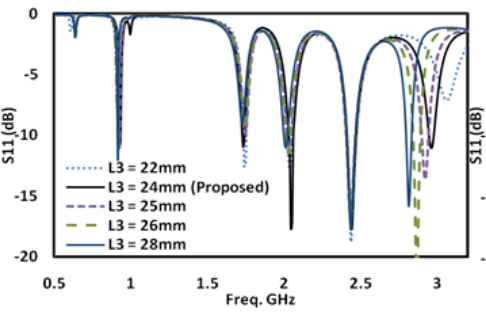

(d)

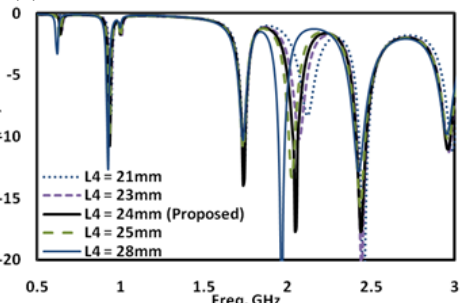

(e)

Fig. 4. Simulated effects of varying (a) $\mathrm{W}_{1}$ on $0.92 \mathrm{GHz}$, (b) $\mathrm{L}_{1}$ on $2.4 \mathrm{GHz}$, (c), $\mathrm{L}_{2}$ on $1.7 \mathrm{GHz}$ (d) $\mathrm{L}_{3}$ on $2.9 \mathrm{GHz}$ and (e) $\mathrm{L}_{4}$ on $1.98 \mathrm{GHz}$

TABLE II: EFFECTS OF CHANGING $\mathrm{W}_{1}, \mathrm{~L}_{1}, \mathrm{~L}_{2}, \mathrm{~L}_{3}$ AND L $\mathrm{L}_{4}, \mathrm{ON} \mathrm{S}_{1}$

\begin{tabular}{|c|c|c|c|c|c|}
\hline Parameters & $0.92 \mathrm{GHz}$ & $1.73 \mathrm{GHz}$ & $1.98 \mathrm{GHz}$ & $2.4 \mathrm{GHZ}$ & $2.9 \mathrm{GHz}$ \\
\hline $\mathrm{W}_{1}$ & $820-990 \mathrm{MHz}(18.78 \%)$ & Fixed & Fixed & Fixed & Fixed \\
\hline $\mathrm{L}_{1}$ & Fixed & Fixed & Fixed & $2310-2580 \mathrm{MHz}(11 \%)$ & Fixed \\
\hline $\mathrm{L}_{2}$ & Fixed & $1550-1948 \mathrm{MHz}(22.75 \%)$ & Fixed & Fixed & Fixed \\
\hline $\mathrm{L}_{3}$ & Fixed & Fixed & $1952-2044 \mathrm{MHz}(4.51 \%)$ & Fixed & Fixed \\
\hline $\mathrm{L}_{4}$ & Fixed & Fixed & Fixed & Fixed & $2800-3044 \mathrm{MHz}(8.21 \%)$ \\
\hline Variation range & $6-10 \mathrm{~mm}$ & $18-28 \mathrm{~mm}$ & $21-28 \mathrm{~mm}$ & $20-28 \mathrm{~mm}$ & $22-28 \mathrm{~mm}$ \\
\hline
\end{tabular}

\section{ReConfigurable Multiband Antenna}

\section{A. Design of Reconfigurable Multiband Antenna}

The results obtained in the previous section are used here to design a frequency-reconfigurable antenna. The dimensions used to design our frequency-reconfigurable antenna here, as shown in Fig. 5, are same as those of the fixed design, listed in Table I. Four varactors, numbered 1, 2, 3, and 4, are placed at the inputs of the sub-patches. The positions of the varactors and the capacitor on the antenna are optimized so that the maximum tunable ranges with independent control can be accomplished. A surface-mount-ceramic-chip capacitance is used for blocking the DC signal from the biased circuits for the varactors, preventing the $\mathrm{DC}$ signal from flowing to the antenna while allowing the radio-frequency (RF) signal to go through. The inductors $\mathrm{L}_{1}, \mathrm{~L}_{2}, \mathrm{~L}_{3}, \mathrm{~L}_{4}$, and $\mathrm{L}_{5}$ are used as RF chokes, providing low impedance for the DC signal and high impedance for the $R F$ signal. The resistors $R_{1}, R_{2}, R_{3}, R_{4}$, and $R_{s}$ are used to give extra protection to the varactors from being damaged. Figure 5 shows a detailed structure of the bias network. The electromagnetic simulation tool HFSS from ANSYS [36] is used to study antenna performance. Just to prove our design concept, we use the practical varactors BB184 from Philips, with the capacitance versus DC characteristic shown in Fig. 6. It is difficult to model the packaging of the capacitor in a full-wave solver, so the varactors are modeled using the resistance, inductance, and capacitance (RLC) boundary sheet, which gives $0.6 \mathrm{nH}$ for inductance and $0.65 \mathrm{ohm}$ for resistance, and Fig. 6 for the characteristic of the varactors in reverse bias. The varactor has capacitances ranging from 2 to $14 \mathrm{pF}$ for the biased voltages from 14 to $1 \mathrm{~V}$.

The reflection coefficient $\mathrm{s}_{11}$ and insertion loss $\mathrm{s}_{21}$ have been

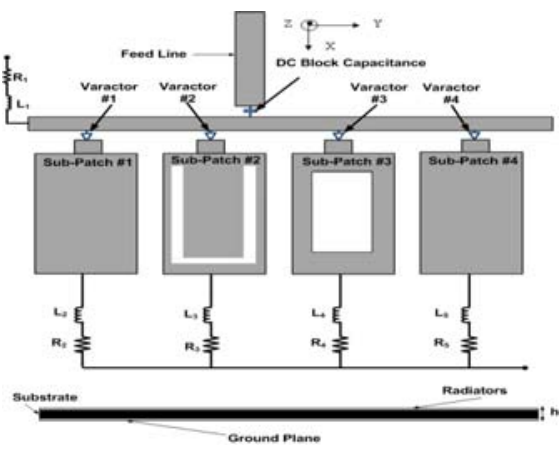

Fig. 5. Proposed reconfigurable design

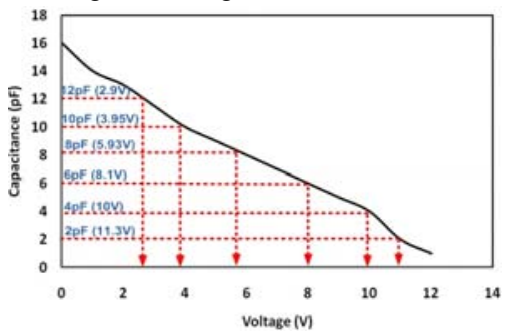

Fig. 6. Capacitance versus DC bias voltage for varactor (from BB184 data sheet)

measured as follows. A $50-\Omega$ microstrip line is fabricated on a PCB. A small slot is cut in the middle of the line to make it two halves of equal length. A DC biased varactor is then placed over the slot to join them together. A network analyzer is used to measure the S-parameters with the biased voltage varied from 14 to $1 \mathrm{~V}$ corresponding to 2 to $14 \mathrm{pF}$. Results show that, with all the biased voltages tested, the varactor has a maximum insertion loss of $0.12 \mathrm{~dB}$ at around $2 \mathrm{GHz}$.

Note that we use practical varactors in our design to prove our design concept. These varactors may not be able to handle 


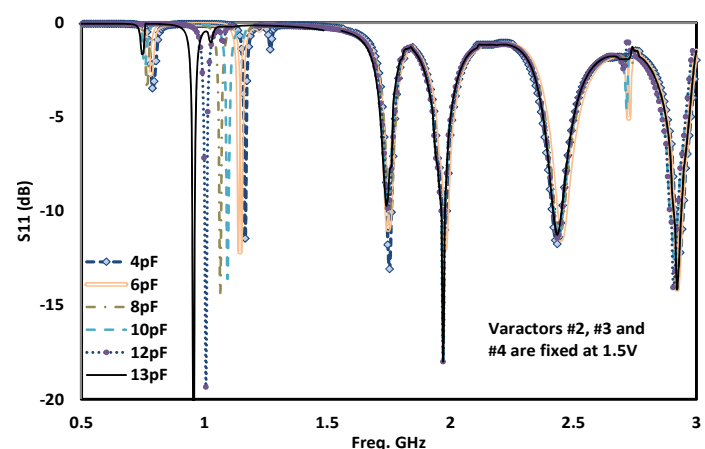

(a)

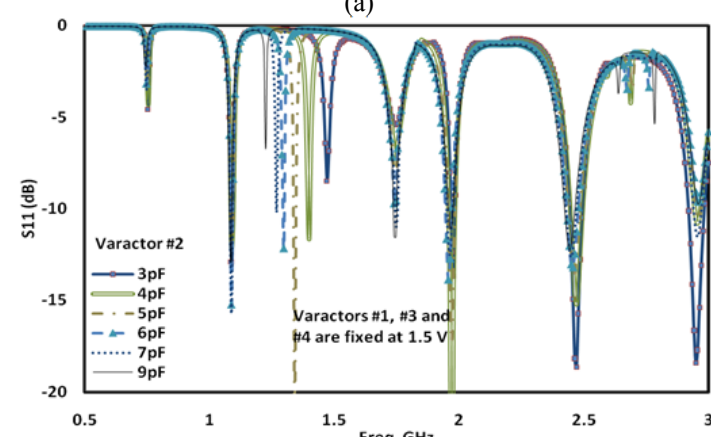

(c)

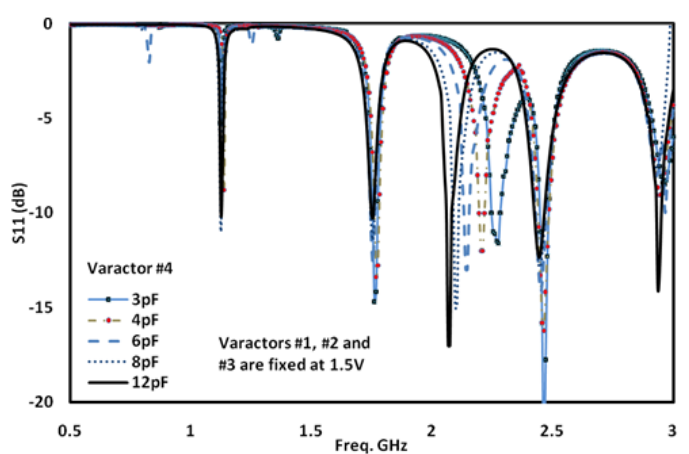

(b)

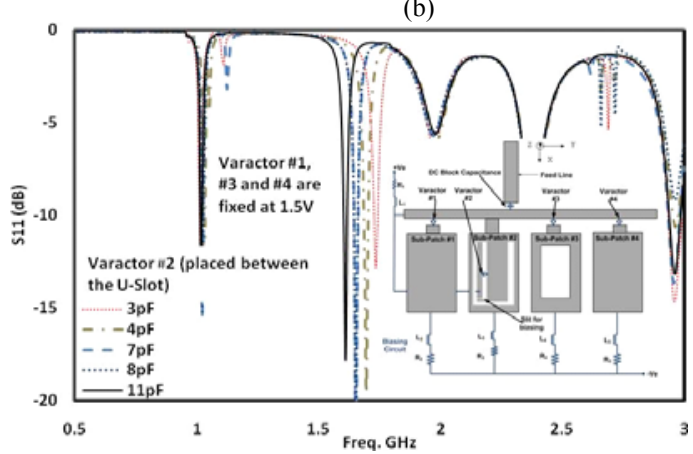

(d)

Fig. 7. Measured $s_{11}$ for reconfigurable design with independent control using (a) varactor 1, (b) varactor 4, (c) varactor 2 (at the input of sub-patch 2 ), and (d) varactor 2 (re-located on the U-slot).

high power such as $2 \mathrm{~W}$, but there are high-power varactors that can handle power of up to $4 \mathrm{~W}$ [37].

\section{$B$. Independent Tuning and Control Range}

When a DC biased voltage of $1 \mathrm{~V}$ is applied to all varactors, simulation results have shown that all the resonant frequencies remain the same as those in the fixed antenna design, i.e., the varactors under such biased condition have no effect on the resonant frequencies. However, if the biased voltage of all varactors is increased to about $1.5 \mathrm{~V}$ simultaneously, all resonant bands slightly shift up, with the tuning ranges already shown in [31]. Here, we study the tuning range for each band using the corresponding varactor, at the same time keeping all other bands fixed. To study the tuning range of band 1 at 0.92 $\mathrm{GHz}$, we vary the biased voltage for varactor 1 , while keeping the biased voltages for other varactors at $1.5 \mathrm{~V}$ (the other varactors can be fixed at any other biased voltages; here we choose 1.5 V just as an example). Figure 7(a) shows the effect of varying the capacitance of varactor 1 on the resonant frequency $0.92 \mathrm{GHz}$ band. It can be seen that the $0.92 \mathrm{GHz}$ band can be independently tuned between 0.92 and $1.16 \mathrm{GHz}$ without much disturbance to the other four frequency bands. For the tuning range of band 3 at $1.98 \mathrm{GHz}$, the biased voltage for varactor 4 is varied. We also fix the biased voltage for other varactors at $1.5 \mathrm{~V}$, which slightly shifts all five bands: bands $1,2,3,4$, and 5 to $1.08,1.75,1.99,2.48$, and $2.98 \mathrm{GHz}$, respectively. Figure 7(b) shows the results. It can be seen that band 3 at $1.99 \mathrm{GHz}$ can be tuned independently without much effect on the other four bands. For the tuning range of band 5 at $2.9 \mathrm{GHz}$, the biased voltage for varactor 3 is varied. Results show that for the capacitance varied from 3 to $12 \mathrm{pF}$ the 2.9 $\mathrm{GHz}$ band is moved only by about $3 \%$, which is quite small. (For simplicity, the result is not shown in Fig. 7.) This might be due to the location of the slot, which does not allow the current on this sub-patch to be changed. For the tuning range of band 2, varactor 2 is used. Surprisingly, however, the result in Fig. 7(c) shows that the undesirable frequency band at 1 $\mathrm{GHz}$ is enhanced and moved, instead of band 2 at $1.73 \mathrm{GHz}$. The reason is that the varactor capacitance only improves the matching at this $1 \mathrm{GHz}$ frequency. To solve this problem, we re-designed a U-slot on sub-patch 2 and moved the varactor to the slot gap, as shown in Fig. 7(d), which also shows the effect of varying the capacitance of varactor 2 on the resonant frequency $1.73 \mathrm{GHz}$ band. It can be seen that now the 1.73 $\mathrm{GHz}$ band can be tuned independently from 1.73 to $1.56 \mathrm{GHz}$, while the other four bands remain unchanged. Table III summarizes these results.

Simulation was also carried out on this antenna in a similar manner, using the varactor model described previously, and the simulated results match well with the measured results. For simplicity, we show only the measured results in this paper.

Notice that the bandwidths $\left(\mathrm{s}_{11}<-10 \mathrm{~dB}\right)$ for these tunable bands, i.e., bands 1, 2, 4, and 5, are quite narrow at 45, 61, 70, and $110 \mathrm{MHz}$, respectively, as shown in Fig. 7. However, the tunable ranges of these bands are quite large. The overall bandwidths achieved by superposing the individual bandwidths over the tunable ranges are approximately $23.5 \%$, $10.3 \%, 13.5 \%$, and $3 \%$, for $0.93,1.73,1.98$, and $2.9 \mathrm{GHz}$, respectively. Although the tunable ranges (or operational bandwidths) of the individual bands are quite large, any applications that utilize the antenna are still limited to a few percentage bandwidths of the tuned center frequencies. However, for narrowband mobile systems such as TDSCDMA or TDD WCDMA which require only 2 and $5 \mathrm{MHz}$ bandwidth, respectively, to operate, the bandwidths of our proposed antenna are good enough [38]. 
TABLE III: EFFECT OF VARYING CAPACITANCES OF VARACTORS INDEPENDENTLY AND/OR SIMULTANEOUSLY

\begin{tabular}{|c|c|c|c|c|c|}
\hline & Band 1 & Band 2 & Band 3 & Band 4 & Band 5 \\
\hline Varactor 1 & $920-1165 \mathrm{MHz}$ & Fixed & Fixed & Fixed & Fixed \\
\hline Varactor 2 & Fixed & $1560-1730 \mathrm{MHz}$ & Fixed & Fixed & Fixed \\
\hline Varactor 3 & Fixed & Fixed & Fixed & Fixed & $2900-2990 \mathrm{MHz}$ \\
\hline Varactor 4 & Fixed & Fixed & $1980-2267 \mathrm{MHz}$ & Fixed & Fixed \\
\hline Bandwidth covered & $23.5 \%$ & $10.3 \%$ & $13.5 \%$ & -- & $3 \%$ \\
\hline
\end{tabular}

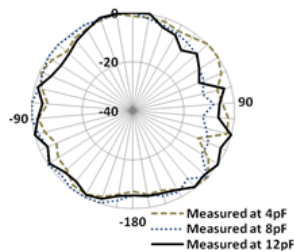

$\mathrm{X}-\mathrm{Z}$

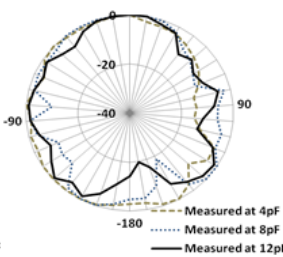

(a)

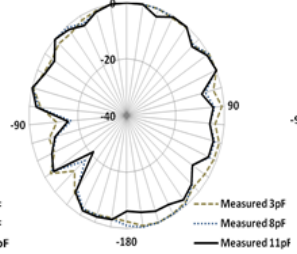

$\mathrm{X}-\mathrm{Z}$

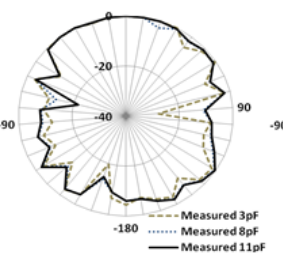

(b)

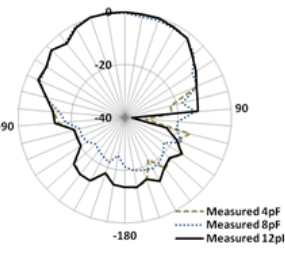

$\mathrm{X}-\mathrm{Z}$

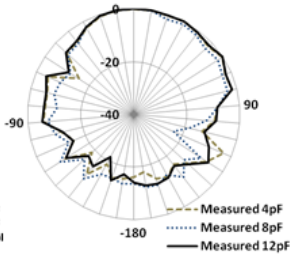

(c)

$\mathrm{Y}-\mathrm{Z}$

Fig. 8. Measured Co-Pol radiation patterns for reconfigurable design for $\mathrm{X}-\mathrm{Z}$ and $\mathrm{Y}-\mathrm{Z}$ planes with different capacitance values at (a) band 1, (b) band 2, and (c) band 3

\section{Simulated AND MEAsured PERformanCES FOR FiXed AND RECONFIGURABLE DESIGNS}

The radiation patterns of the fixed and reconfigurable designs are studied by simulation and measurements. For the fixed design, the normalized measured and simulated radiation patterns for co-polarizations and cross-polarizations in the $\mathrm{X}-\mathrm{Z}$ and $\mathrm{Y}-\mathrm{Z}$ planes are shown in [30]. For the reconfigurable design, we studied the effects of varactor capacitance on the radiation patterns in three bands, i.e., bands 1,2 , and 3 as shown in Fig. 8(a) to (c). The study was not done for band 4 (which is not tunable) or band 5 (which has a very small tunable range of only $3 \%$ ). The measured gains for the fixed design are $-4.2 \mathrm{dBi}$ at $0.92 \mathrm{GHz}, 0.95 \mathrm{dBi}$ at $1.73 \mathrm{GHz}, 1.19 \mathrm{dBi}$ at $1.98 \mathrm{GHz}, 0.91 \mathrm{dBi}$ at $2.4 \mathrm{GHz}$, and $2 \mathrm{dBi}$ at $2.9 \mathrm{GHz}$, whereas the corresponding simulated gains are $-1.0,1.6,1.2$, 1.05 , and $2.2 \mathrm{dBi}$, respectively. The differences between the simulated and measured gains might be due to the following reasons. i) The loss of the FR-4 material used varies with frequency, but, in simulation, a fixed tangent loss was assumed at all frequencies. ii) The cable and connector were used in measurements, while they were not taken into account in simulation. iii) The fabrication tolerance in the prototype would also affect the measured results. iv) There would be tolerances in the measurement system. For the reconfigurable design, simulation results show that the peak gains are less than those of the fixed design. The simulated efficiency in the fixed design ranges from $39 \%$ to $59 \%$. With a varactor capacitance of $14 \mathrm{pF}$, the simulated peak gains for the five bands are $-2.2,-0.42,-0.2,-0.6$, and $0.4 \mathrm{dBi}$, and the simulated efficiency ranges from $29 \%$ to $50 \%$, having a drop of about $10 \%$ compared with those of the fixed design. The resistance of the varactor could affect radiation efficiency, as demonstrated in [28], [39], and [40], which showed that a high resistance had significant effects on the gain and radiation efficiency of the antenna. In our design, however, the resistance in the varactor diodes is quite small at $0.65 \mathrm{ohm}$ and so has much less effect on efficiency. In fact, our further studies show that radiation efficiency would increase by $5 \%$ if this resistance is reduced to zero.

\section{CONCLUSIONS}

This paper has presented the designs of compact five-band printed antennas for fixed or reconfigurable communications systems. The fixed design has five frequency bands at 0.92 , $1.73,1.98,2.4$, and $2.9 \mathrm{GHz}$. The design procedure for the antenna has been described in detail. By adding four varactors to the design, it becomes a reconfigurable design, enabling the four bands to be electrically and independently tuned over wide ranges. Both designs have been fabricated and measured. The measured and simulated results are in good agreement.

\section{ACKNOWLEDGMENTS}

The measurements at the NPL SMART chamber were supported by the Measurements for Innovators (MFI) program and the National Measurement Office, an Executive Agency of the Department for Business, Innovation and Skills. The authors acknowledge Skyworks Solutions Inc. for providing samples used in this work.

\section{REFERENCES}

[1] M Sanad, "Double C-Patch Antennas Having Different Aperture Shapes," IEEE Proceedings on Antennas and Propagation, pp.2116-2119, June 1995.

[2] Y. Lee and J. Sun, "A New Printed Antenna for Multiband Wireless Applications," IEEE Antennas and Wireless Propagation Letters, vol. 8, pp. 402-405, 2009

[3] C. L. Mak, R. Chair, K. F. Lee, K. M. Luk and A. A. Kishk, "Half U-slot patch antenna with shorting wall," Electronics Letters, vol. 39, pp. 17791780, 2003.

[4] H. F. AbuTarboush, R. Nilavalan, D. Budimir and H. S. Al-Raweshidy, "Double U-Slots Patch Antenna for Tri-Band Wireless Systems," John and Wiley International Journal of RF and Microwave Computer-Aided Engineering, Vol. 20, no. 3, pp. 279-285, May 2010.

[5] M. Ali, G. Hayes, H. Hwang and R. Sadler, "Design of a multiband internal antenna for third generation mobile phone handsets," IEEE Transactions on Antennas and Propagation, vol.51, pp.1452-1461, 2003.

[6] S. Chen, Y. Jiao, W. Wang and F. Zhang, "Modified T-shaped planar monopole antennas for multiband operation," IEEE Transactions on Microwave Theory and Techniques, vol. 54, pp. 3267-3270, 2006.

[7] A. Sheta, "A novel H-shaped patch antenna," Microwave Optical Technology Letter P.62-65, 2001.

[8] H. Elsadek and D. Nashaat, "Multiband and UWB V-Shaped Antenna Configuration for Wireless Communications Applications," IEEE Antennas and Wireless Propagation Letters, vol. 7, pp. 89-91, 2008.

[9] J. Anguera, C. Puente, C. Borja and J. Soler, "Dual-Frequency BroadbandStacked Microstrip Antenna Using a Reactive Loading and a Fractal- 
Shaped Radiating Edge," IEEE Antennas and Wireless Propagation Letters, vol. 6, pp. 309-312, 2007.

[10] J. Gemio, J. Granados and J. Castany, "Dual-Band Antenna with FractalBased Ground Plane for WLAN Applications," IEEE Antennas and Wireless Propagation Letters, vol. 8, pp. 748-751, 2009

[11] D. Kim, J. Lee, C. Cho and T. Lee, "Design of a Compact Tri-Band PIFA Based on Independent Control of the Resonant Frequencies," IEEE Transactions on Antennas and Propagation, vol. 56, pp. 1428-1436, 2008

[12] Z. Ying, "Multi frequency-band antenna," Patent No WO01/91 233, May 2001. Z. Ying and A. Dahlstroem, "Multi frequency band antenna for mobile telephone," patent No WO200191233-A; EP1168491-A WO200191233-A1

13] H. F. AbuTarboush, R. Nilavalan, T. Peter and S. W. Cheung, "Multiband Inverted-F Antenna with Independent Bands for Small and Slim Mobile Handsets," IEEE Tran. on Antennas and Propagation, Vol. 59, No. 7, Jul. 2011.

[14] S. Yang, C. Zhang, H. Pan, A. Fathy and V. Nair, "Frequencyreconfigurable antennas for multiradio wireless platforms," IEEE Microwave Magazine, vol. 10, pp. 66-83, 2009.

[15] Y. Guo, A Weily, "A Frequency-Reconfigurable Quasi-Yagi Dipole Antenna," IEEE Antennas and Wireless Propagation Letters, vol.9,pp.883-886, 2010

[16] H. F. AbuTarboush, R. Nilavalan, K. Nasr, S. W. Cheung, T. Peter, H. Al-Raweshidy, and D. Budimir, "Reconfigurable Tri-Band H-Shaped Antenna with Frequency Selectivity Feature for Compact Wireless Communication Systems," IET Microwave Antennas and Propagation, vol.5, no.14, pp.1675-1682, November 18. 2011.

[17] S. Yang, A. Kishk, K. Lee, "Frequency Reconfigurable U-Slot Microstrip Patch Antenna," IEEE Antennas and Wireless Propagation Letters, vol.7, pp.127-129, 2008.

[18] S. Shynu, G. Augustin, C. Aanandan, P. Mohanan, K. Vasudevan, "Cshaped slot loaded reconfigurable microstrip antenna," Electronics Letters, vol.42, no.6, pp. 316-318, 16 March 2006.

[19] V. Nguyen, R. Bhatti, S. Park, "A Simple PIFA-Based Tunable Internal Antenna for Personal Communication Handsets," IEEE Antennas and Wireless Propagation Letters, vol.7, pp.130-133, 2008.

[20] M. Lai, T. Wu, J. Hsieh, C. Wang, S. Jeng, "Design of reconfigurable antennas based on an L-shaped slot and PIN diodes for compact wireless devices," IET Microwaves Antennas and Propagation, vol.3, no.1, pp.47-54, February 2009.

[21] Z. H. Hu, P. S. Hall, and P. Gardner, "Novel reconfigurable dipolechassis antennas for small terminal MIMO applications", Electronics Letters, Vol.47, No.17, pp. 953-955, August 2011.

[22] N. Behdad, K. Sarabandi, "Dual-band reconfigurable antenna with a very wide tunability range," IEEE Transactions on Antennas and Propagation, vol.54, no.2, pp. 409- 416, Feb. 2006.

[23] Z. H. Hu, C. T. P. Song, J. Kelly, P. S. Hall, and P. Gardner, "Wide tunable dual-band reconfigurable antenna," Electronics Letters, vol. 45 , Issue 22, pp. 1109-1110, Oct. 2009

[24] k M. Alkanhal and A. F. Sheta, "A Novel Dual-Band Reconfigurable Square-Ring Microstrip Antenna," Progress In Electromagnetics Research, PIER 70, 337-349, 2007.

[25] A. Mak, C. Rowell, R. Murch, M. Chi-Lun, "Reconfigurable Multiband Antenna Designs for Wireless Communication Devices," IEEE Trans. on Antennas and Propagation, vol.55, no.7, pp.1919-1928, July 2007.

[26] D. Anagnostou, A. Gheethan, "A Coplanar Reconfigurable Folded Slot Antenna Without Bias Network for WLAN Applications," IEEE Antennas and Wireless Propagation Letters, vol.8, pp.1057-1060, 2009.

[27] H. F. AbuTarboush, R. Nilavalan, S. W. Cheung, K. M. Nasr, T. Peter, D. Budimir, H. Al-Raweshidy, "A Reconfigurable Wideband and Multiband Antenna Using Dual-Patch Elements for Compact Wireless Devices," IEEE Transactions on Antennas and Propagation, vol.60, no.1, pp.36-43, Jan. 2012

[28] Q. Pei-Yuan, A. Weily, Y. Guo, T. S. Bird, L. Chang-Hong, "Frequency Reconfigurable Quasi-Yagi Folded Dipole Antenna," IEEE Transactions on Antennas and Propagation, ,vol.58,no.8, pp.2742-2747, Aug. 2010.

[29] S Shynu, G.Augustin, C.Aanandan, P.Mohanan, K.Vasudevan, "Development of a varactor-controlled dual-frequency reconfigurable microstrip antenna," Micro. and Opti. Tech. Letters V.46, no.4, P.375377, 2005.

[30] H. F. AbuTarboush, R. Nilavalan, K. Nasr, H. Al-Raweshidy, D. Budimir, M. Alexander, "A compact printed antenna for multiband wireless applications," Inter. Workshop on Antenna Technology, 2010.
[31] H. F. AbuTarboush, R. Nilavalan, K. Nasr, H. S. Al-Raweshidy, D. Budimir, "Widely tunable multiband reconfigurable patch antenna for wireless applications," Proceedings of the Fourth European Conference on Antennas and Propagation (EuCAP), 2010.

[32] N. Bayatmaku, P. Lotfi, M. Azarmanesh, S. Soltani, "Design of Simple Multi-Band Patch Antenna for Mobile Communication Applications using New E-shape Fractal," IEEE Antennas and Wireless Propagation Letters, no.99, pp.1.

[33] R. Sujith, V. Deepu, D. Laila, C. Aanandan, K. Vasudevan, P. Mohanan, "A compact dual-band modified T-shaped CPW-fed monopole antenna," Micro. and Opti. Tech. Letters, vol.51, no.4, pp.937-939, 2009.

[34] Bau-Yi Lee, Wen-Shan Chen, Wen-Lin Chang, Fu-Lai Yen, Yuan-Chih Lin, "Five-band printed antenna for mobile phone and WLAN applications," IEEE International Symposium Antennas and Propagation Society (APSURSI), pp.1-4, 2010.

[35] S. Lee, H. Park, S. Hong, and J. Choi, "Design of a Multiband Antenna using a Planner Inverted-F Structure," The 9th International Conference on Advanced Communication Technology, vol. 3, pp.1665-1668, 2007.

[36] Ansoft Corporation HFSS [Online]. Available: http://www.ansoft.com.

[37] Y. Lu, L. Katehi, D. Peroulis, "High-power MEMS varactors and impedance tuners for millimeter-wave applications," IEEE Transactions on Microwave Theory and Techniques, vol.53, no.11, pp. 3672- 3678, Nov. 2005.

[38] B Li, D Xie, S. Cheng, J Chen and P Zhangm "Recent Advances on TDSCDMA in China", IEEE Communications Magazine, 30-37, 2005.

[39] P. Chi, R. Waterhouse, T. Itoh, "Compact and Tunable Slot-Loop Antenna," IEEE Transactions on Antennas and Propagation, no.99, pp.1.

[40] A. Weily, T. S. Bird, Y. Guo, "A Reconfigurable High-Gain Partially Reflecting Surface Antenna," IEEE Transactions on Antennas and Propagation, vol.56, no.11, pp.3382-3390, Nov. 2008.

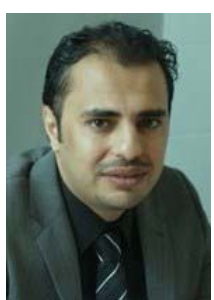

Hattan F. Abutarboush (M’07) received the B.Sc (Eng) Honours degree in Electrical Communications and Electronics Engineering from Greenwich University, London, UK, in 2005 and the MSc degree in Mobile Personal and Satellite Communications from the Department of Electrical and Electronics Engineering, Westminster University, London, UK, in 2007. He received the $\mathrm{PhD}$ degree from the Department of Electronics and Computer Engineering in Antennas and Propagation from Brunel University, London, UK, in July 2011. His PhD research work was mainly on Fixed and Reconfigurable Multiband Antennas. He was a research visitor to Hong Kong University in Hong Kong and National Physical Laboratory (NPL), Teddington, UK. He also worked as a research associate for the American University in Cairo (AUC) from April to July 2011.

Dr. Abutarboush is a research fellow at King Abdullah University of Science and Technology (KAUST). He has published several technical papers in international journals and conferences. He also has served as reviewer for different international journals and conferences in the areas of antennas and propagation $\mathrm{He}$ is a member of IEEE and IET. His current research interests lie in the design of reconfigurable antennas, multiband antennas, antennas for mobile phones, miniaturized antennas, smart antennas, antenna arrays, EBG, $\mathrm{RF} /$ microwave circuit design, mm-wave antennas, on-chip antennas and lens antennas.

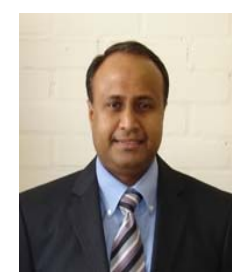

R. Nilavalan (M'05, SM'10) received the B.Sc. Eng in Electrical and Electronics Engineering from University of Peradeniya, SriLanka in 1995 and PhD in Radio Frequency Systems from University of Bristol, Bristol, UK in 2001. From 1999 to 2005 he was a researcher at the Centre for Communications Research (CCR) at University of Bristol, UK. At Bristol, his research involved theoretical and practical analyses of post reception synthetic focussing concepts for near-field imaging and research on numerical FDTD techniques. Since 2005, he has been with the Electronics and Computer Engineering subject area, Brunel University, where he is currently a senior lecturer in wireless communications. His main research interests include antennas and propagation, microwave circuit designs, numerical electromagnetic modelling and wireless communication systems. He has published over 90 papers and articles in international conferences and journals in his research area.

Dr. Nilavalan was a member of the European commission, Network of Excellence on Antennas (2002 - 2005) and a member of the IET. 


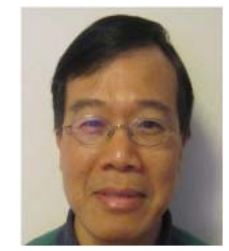

S. W. Cheung received the BSc degree with First Clas Honours in Electrical and Electronic Engineering from Middlesex University, U.K. in 1982 and the $\mathrm{PhD}$ degree from Loughborough University of Technology, U.K. in 1986. From 1982 to 1986, he was a research assistant in the Department of Electronic and Electrical Engineering at Loughborough University of Technology, where he collaborated with Rutherford Appleton Laboratory and many UK universities to work a project for new generations of satellite systems. During the period from 1986 and 1988, he was a post-doctorate research assistant with the Communications Research Group of King's College, London University, working on research for future generations of satellite systems. In 1988, he joined the Radio and Satellite Communications Division in British Telecom Research Laboratories (now British Telecom Laboratories), as an assistant executive engineer.

Dr Cheung is an Associate Professor at the University of Hong Kong and in charge of the Microwave, RF Frequency and Telecom Laboratories. His current research interests include antenna designs, $2 \mathrm{G}, 3 \mathrm{G}$ and $4 \mathrm{G}$ mobile communications systems, MIMO systems and satellite communications systems, predistortion of high power amplifiers and e-learning. He has published over 150 technical papers in international journals and conferences in these areas. He also has served as reviewer for different international journals and conferences in the areas of antennas and propagation and mobile communications. He is a senior member of the IEEE and has been serving the IEEE in Hong Kong for the past twenty years. In 2009 and 2010, he was the Chairman of the IEEE Hong Kong Joint Chapter on Circuits and Systems and Communications. Since 2011, he has been the Treasurer of the IEEE Hong Kong Section and help organizing different international conferences.
Karim M. Nasr was awarded the Ph.D. degree in 2005 from the University of Manchester, UK, on "Smart Antenna Systems for Indoor Wireless Networks". He previously held postdoctoral research posts at the University of Manchester, Brunel University and $\mathrm{BBC}$ Research investigating future wireless and broadcast communication systems and applications through a number of UK and European research projects. He was also a visiting researcher at the antennas and propagation of Aalborg University, Denmark. Dr. Karim Nasr is presently a Higher Research Scientist at the National Physical Laboratory (NPL), Teddington, UK, investigating advanced wireless communication systems and high precision large volume laser based metrology. His research interests include: propagation measurements and modelling, Digital Signal Processing (DSP) and metrology for broadband wireless and broadcast systems, smart antennas and multiuser MIMO systems, UWB, joint Physical / MAC layers optimization, coexistence of wireless systems, advanced antenna metrology and laser based coordinate metrology. Dr. Nasr is a reviewer for several IEEE transactions and a member of TPC of several international conferences. Dr. Nasr is a chartered engineer (CEng), a senior member of the Institute of Electrical and Electronics Engineers (IEEE), a member of the Institution of Engineering and Technology (the IET) and European COST Actions on wireless communication systems. 